The Egyptian Journal of Hospital Medicine (January 2019) Vol. 74 (4), Page 735-743

\title{
Surgical Outcomes of Right Anterolateral Minithoracotomy versus Median Sternotomy in Atrial Septal Defect
}

\author{
Hossam ElSayed Abd Al-Fattah, Mohammed Eldesoky Sharaa, Mohammed Abd Al-Fattah \\ Department of Cardiothoracic Surgery, Faculty of Medicine, Al-Azhar University \\ Corresponding author: Hossam Elsayed Abd Al Fattah, Mobile: 01060792731, Email:hossamelsayed1st@gmail.com
}

\begin{abstract}
Background: the atrial septal defect repair has been traditionally approached through a median sternotomy. However, significant advances in surgical optics, instrumentation, tissue tele manipulation and perfusion technology have allowed for atrial septal defect repair to be performed by using progressively smaller incisions including the minithoracotomy. Aim of the study: this study aimed to compare the surgical outcome of right anterolateral minithoracotomy versus median sternotomy in atrial septal defect repair. Methods: this study was done in Department of Cardiothoracic Surgery at Elhussen Hospital, Al-Azhar University, after approval of the local ethical committee in the period between July 2017 till July 2018. 30 patients with ASD required ASD repair were included in this study for operative and short term postoperative results to evaluate the impact of two approaches of repair on quality of life of patients who survived the operation was studied. Results: The patients in both groups were similar in age preoperative comorbidities and ejection fraction but more female s were in Right anterolateral mini -thoracotomy group. There was a highly statistically significant prolonged pump-run time in the thoracotomy group than the sternotomy group with $\mathrm{p}$-value $1 / 40.004$. Interestingly, in the thoracotomy group, mechanical ventilation time (hours) was shorter with p-value $1 / 40.0$ 02. There were similar blood transfusion rate, chest tube drainage, intensive care unit stay and hospital length of stay. However, more wound infection was found in the sternotomy group which was statistically significant ( $p$-value $1 / 40.035)$. There were no patients requiring conversion to full sternotomy, no residual defect across the atrial septum and all patients were alive on a month follow-up of the hospit al discharge. Conclusion: right antero-lateral mini-thoracotomy technique for atrial septal defect anomaly closure was safe and reliable technique as sternotomy incision. Apart from its restricted operating field and longer pump-run time, it kept the sternal integrity, it had better esthetic incision, it reduced wound infection and the need for analgesia. Moreover, it is associated with an early recovery and short ICU stay.
\end{abstract}

KEYWORDS atrial septal defect, right anterolateral thoracotomy

\section{Introduction}

Atrial septal defect (ASD) is one of the most common congenital heart defects. ASD was among the first anomalies to be corrected by surgical treatment ${ }^{(\mathbf{1})}$.

Sternotomy technique had been the gold standard in cardiac surgery and generally provides an unobstructed view of the heart. This is the currently used method in which all surgeons are trained and perform cardiac surgery across the world $^{(2)}$.

Built on the premise that less invasive surgery could expedite postoperative recovery aiming to a reduction in surgical trauma with limited access techniques, resulting in reduced hospital stays, reduced hospital costs, improved cosmosis and increased patient satisfaction ${ }^{(3)}$.Currently, different trans-catheter closure procedures have been introduced with outstanding long-term outcomes, but they are still limited to apply for all patients to avoid serious complications (4). Moreover, RALT for ASD repair gives an excellent exposure and the cannulation can be achieved either centrally or femorally in addition to the cardioplegia delivery to myocardium ${ }^{(5)}$. 


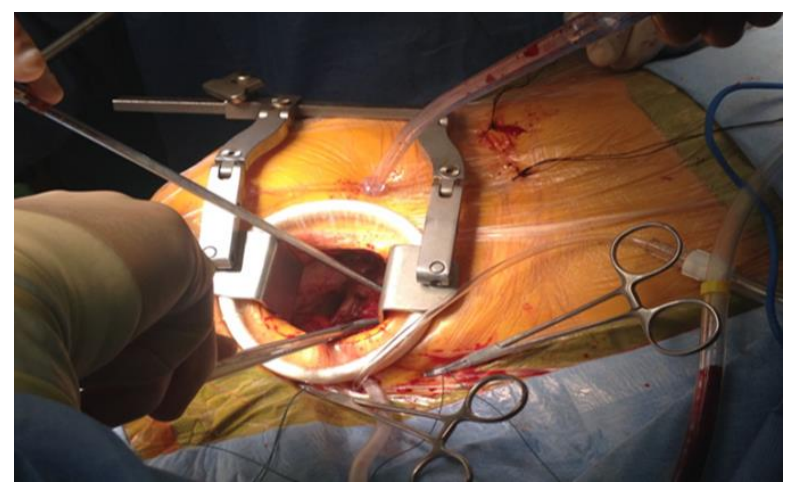

Figure 1: showing the surgical field.

In young patients, like those who undergo ASD closure, femoral vessels cannulation is mostly used ${ }^{\left({ }^{(6)}\right.}$ where there is any harm from retrograde femoral arterial perfusion due to the atherosclerosis process is unlikely to be happened in young patients. However, femoral arterial cannulation is not without complications and arterial spasm due to a small femoral artery ${ }^{(8)}$.

\section{Patients and Methods}

In this study 30 patients with ASD requiring ASD repair were non randomly selected. Fifteen patients underwent ASD repair via standard median sternotomy, the other 15 patients via level I less invasive surgery. Right anterolateral minithoracotomy operations rely on direct vision $(6-12 \mathrm{~cm})$ with femoral artery and vein cannulation. Both groups were operated in Elhussin Hospital. This study was performed during the time from July 2017 till July 2018. The study was approved by the Ethics Board of AlAzhar University.

Inclusion criteria:

Patients came for first-time cardiac surgery.

Patients who had isolated ASD

Patients with age equal to or $>2$ years

Patients had body weight greater than $6 \mathrm{Kg}$

Exclusion criteria:

Patients who had bleeding diathesis

Patients with kidney or liver dysfunction

Patients with chest wall deformity/trauma or radiation

Patients with severe fixed pulmonary hypertension

Obese patients

All our patients were subjected to:

Preoperative assessment:
History taking and routine investigation to prepare for open heart surgery

Complete routine lab, X-ray, ECG, chocardiography.

Intraoperative assessment:

Intraoperative variables, cardiopulmonary bypass (CPB) time,

aortic clamp time., entire operative time and type of closure.

\section{Postoperative assessment:}

Mechanical ventilation time

Chest tube drainage

Allogeneic blood transfusion rat.

Bleeding, re-exploration

Wound infection and/or seroma

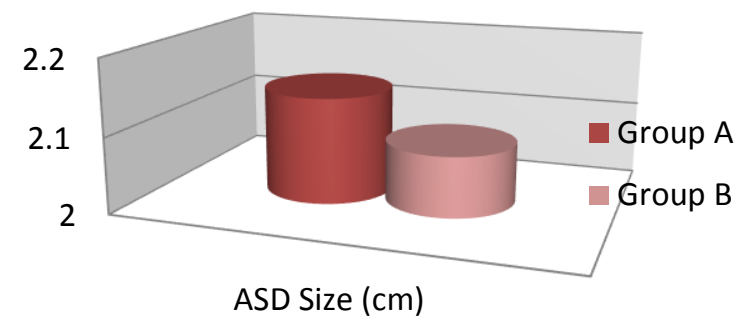

Mortality, intensive care unit (ICU) stay time

Hospital length of stay

Total analgesic requirements

Postoperative complications

Pre-discharge and a one month post discharge echocardiography for detection of any residual shunt.

Assessment of cosmosis, patient perception and pain and satisfaction

RESUlTS

I. Preoperative assessment:

A. Demographic data and clinical characteristics of the patients:

Table 1 showing demographic data and clinical characteristics of the patients

\begin{tabular}{|l|l|l|}
\hline & Group A & Group B \\
\hline Age & $12-47$ & $2-53$ \\
\hline Males & $3(20 \%)$ & $8(53 \%)$ \\
\hline Females & $12(80 \%)$ & $7(47 \%)$ \\
\hline & & \\
\hline
\end{tabular}


Table 2: showing preoperative echocardiogrphic assessment

\begin{tabular}{|l|l|l|l|}
\hline \multicolumn{2}{|l|}{} & Group A & Group B \\
\hline ASD Size (cm) & $2.14 \pm 0.67$ & $2.08 \pm 44$ \\
\hline \multirow{3}{*}{ TR } & Mild & $14(93 \%)$ & $13(86 \%)$ \\
\cline { 2 - 4 } & $\begin{array}{l}\text { Mild to } \\
\text { Moderate }\end{array}$ & $1(7 \%)$ & $1(7 \%)$ \\
\cline { 2 - 4 } & Moderate & $0(0 \%)$ & $1(7 \%)$ \\
\hline PAP & $30-50$ & $25-45$ \\
\hline EF\% & $55-70 \%$ & $50-70 \%$ \\
\hline
\end{tabular}

This table showed that there was no significant difference between the two studied groups regarding ASD size, pulmonary artery pressure (PAP) , tricuspid regurge (TR) and ejection fraction $(\mathrm{EF}) \%$ with p-value $0.718,0.598,0.113$, 0.292; respectively.

Figure 2: showing ASD size in both groups

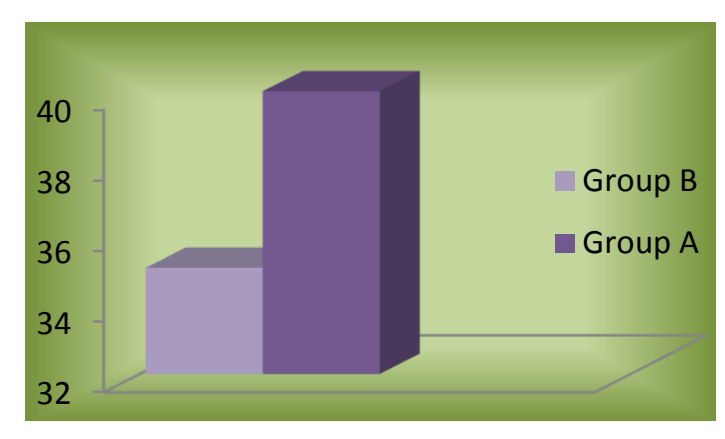

Figure 3: showing PAP in both groups

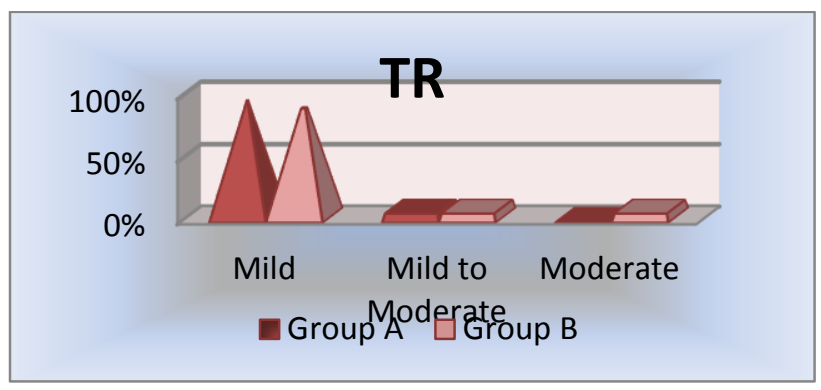

Figure 4 : showing tricuspid repair in both groups

Table 3: showing Intra operative results:

\begin{tabular}{|l|l|l|}
\hline & Group A & Group B \\
\hline $\begin{array}{l}\text { Total bypass } \\
\text { time (mintues) }\end{array}$ & $\begin{array}{l}\text { Mean+SD } \\
57.25 \pm 6.97\end{array}$ & $\begin{array}{l}48.5 \\
\pm 10.77\end{array}$ \\
\hline $\begin{array}{l}\text { Total operative } \\
\text { time (hours ) }\end{array}$ & $3.3 \pm .3$ & $3.43 \pm .47$ \\
\hline $\begin{array}{l}\text { Type of } \\
\text { closure } \\
\text { (pericardial } \\
\text { patch) }\end{array}$ & $15(100 \%)$ & $15(100 \%)$ \\
\hline
\end{tabular}

This table showed that there was a highly significant difference between the two groups of study regarding total bypass time (minute) with p-value 0.004 while, no significant difference was found between the two studied groups regarding total operative time (hours) with $\mathrm{p}$ value 0.320 .

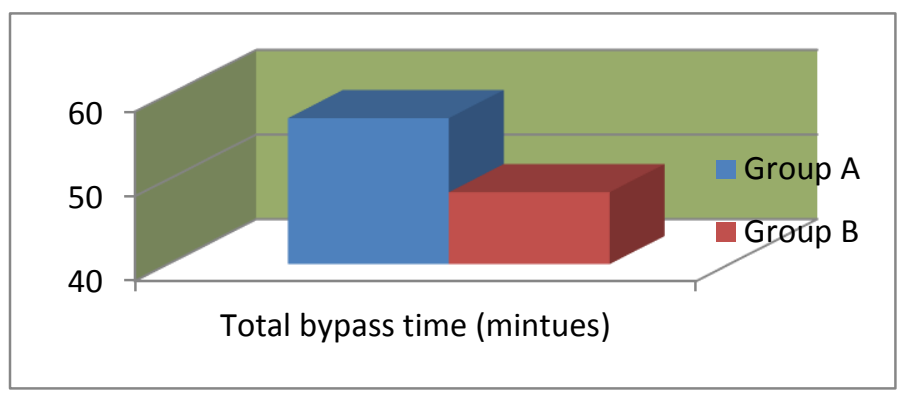

Figure 5 : showing total bypass time in both groups

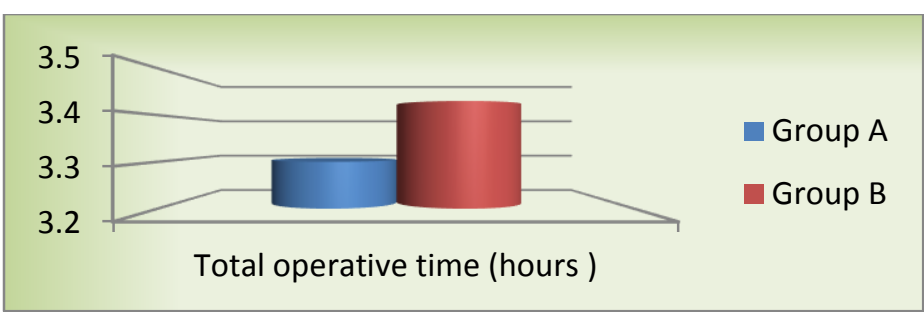

Figure 6: showing total operative time

Table 4: showing cross clamp time and fibrillating time:

\begin{tabular}{|l|l|l|}
\hline & Group A & Group B \\
\hline $\begin{array}{l}\text { Cross clamp } \\
\text { time }\end{array}$ & -- & $31.00 \pm 5.03$ \\
\hline $\begin{array}{l}\text { Fibrilatting } \\
\text { time }\end{array}$ & $35 \pm 5.9$ & -- \\
\hline
\end{tabular}

this table showed that the mean of cross clamp time in sternotomy group was 31.00 and the mean of fibrillating time in thoracotomy group was 35.00. 

incision :

Table 5: showing Length of skin

\begin{tabular}{|l|l|ll|}
\hline & $\begin{array}{l}\text { GROUP } \\
\text { A }\end{array}$ & $\begin{array}{l}\text { GROUP } \\
\text { B }\end{array}$ \\
\hline $\begin{array}{l}\text { RANGE } \\
(\text { CM) }\end{array}$ & $6-12$ & $19-26$ & \\
\hline MEAN \pm SD & $\begin{array}{l}6.92 \pm \\
0.93\end{array}$ & $\begin{array}{l}22.47 \\
2.23\end{array}$ \\
\hline
\end{tabular}

This table showed that Length of the skin incision was compared in the two groups. The mean length of incision in group "I" was $22.47 \pm$ $2.23 \mathrm{~cm}$ ransged from 19 to $26 \mathrm{~cm}$. while in group "II" the mean length was $6.92 \pm 0.93 \mathrm{~cm}$ ranged from 6 to $12 \mathrm{~cm}$ with $\mathrm{P}$ value $<0.01$ ).

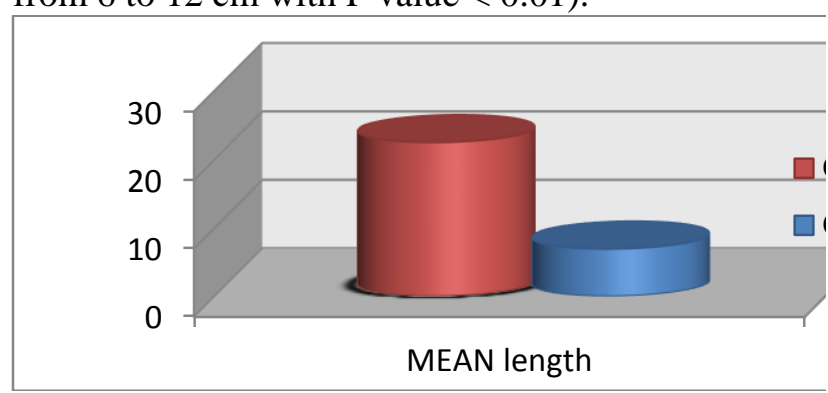

Figure 7: showing Length of skin incision in both groups

Table 6: showing intensive care events

\begin{tabular}{|l|l|l|}
\hline & Group A & Group B \\
\hline $\begin{array}{l}\text { Ventilation } \\
\text { time }\end{array}$ & $4.85 \pm 2.03$ & $6.85 \pm 1.76$ \\
\hline $\begin{array}{l}\text { Total } \\
\text { drainage } \\
(\mathrm{ml})\end{array}$ & $50 \pm 370$ & $50 \pm 350$ \\
\hline $\begin{array}{l}\text { Amount of } \\
\text { transfused } \\
\text { blood (ml) }\end{array}$ & $1075 \pm 244.68$ & $1075.5 \pm 393.88$ \\
\hline $\begin{array}{l}\text { ICU stay } \\
\text { (days) }\end{array}$ & $2.05 \pm .22$ & $2 \pm .32$ \\
\hline $\begin{array}{l}\text { Total hospital } \\
\text { delay (days) }\end{array}$ & $6.8 \pm 2.48$ & $7 \pm 1.38$ \\
\hline
\end{tabular}

This table showed that there was a highly significant difference between the two studied groups regarding ventilation time with $\mathrm{p}$-value 0.002 while no significant difference found between the two groups regarding total drainage, amount of blood transfused to the patients, ICU stay and total hospital stay with p-value 0.364 , $0.649,0.574,0.754$ respectively.

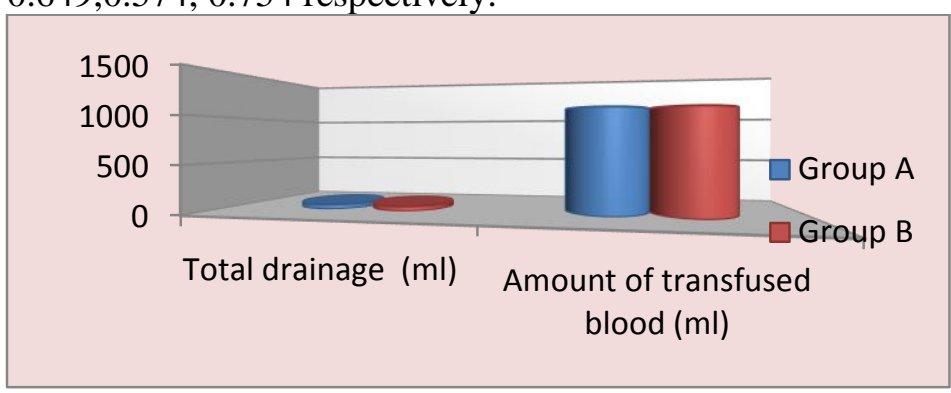

Figure 8: showing total drainage and amount of transfused blood in both groups.

\section{Table 7: showing complications}

\begin{tabular}{|l|l|l|}
\hline & Group A & Group B \\
\hline & 15 & 15 \\
\hline Bleeding & $1(7 \%)$ & $0(0 \%)$ \\
\hline Re-operation & $0(0 \%)$ & $0(0 \%)$ \\
\hline $\begin{array}{l}\text { Wound } \\
\text { infection }\end{array}$ & $0(0 \%)$ & $4(27 \%)$ \\
\hline Mortality & $0(0 \%)$ & $0(0 \%)$ \\
\hline Residual shunt & $0(0 \%)$ & $0(0 \%)$ \\
\hline
\end{tabular}

That table showed that there was a significant difference between the two groups regarding wound infection while, no significant difference was found between the two groups regarding the other studied complications.

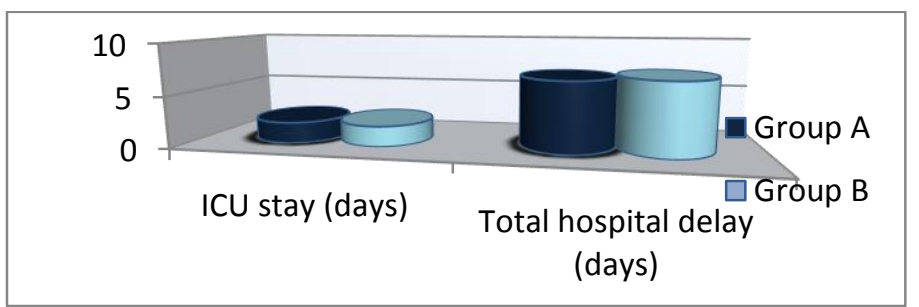

Figure 9: showing ICU stay and total hospital delay

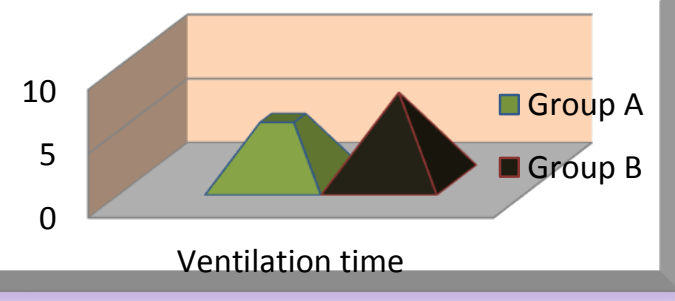

Figure10: showing ventilation time 


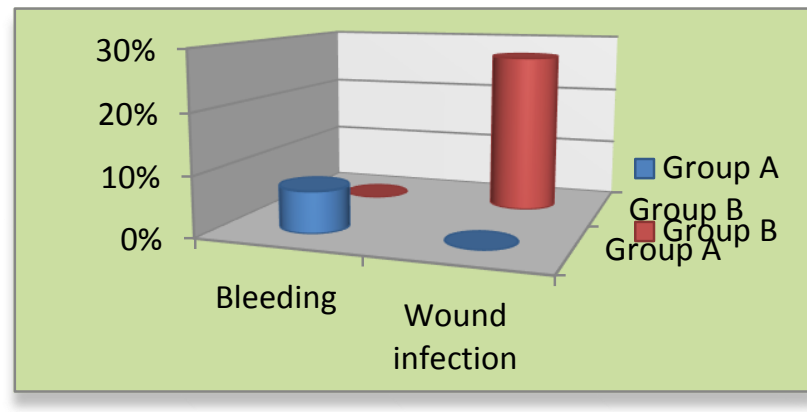

Figure 11: showing bleeding and wound infection in both groups

Table 8 : showing post-operative pain score

\begin{tabular}{|l|l|l|}
\hline & $\begin{array}{l}\text { Group } \\
\mathrm{A}\end{array}$ & $\begin{array}{l}\text { Group } \\
\mathrm{B}\end{array}$ \\
\hline $1^{\text {st }}$ Daypostoperative & $\begin{array}{l}9.6 \pm \\
0.59\end{array}$ & $\begin{array}{l}7.7 \pm \\
0.65\end{array}$ \\
\hline $2^{\mathrm{ND}}$ Daypostoperative & $\begin{array}{l}7.9 \pm \\
0.64\end{array}$ & $\begin{array}{l}5.7 \pm \\
0.97\end{array}$ \\
\hline Pre-discharge & $\begin{array}{l}5.25 \pm \\
1.11\end{array}$ & $\begin{array}{l}3.5 \pm \\
1\end{array}$ \\
\hline
\end{tabular}

Pain score post-operative using the visual analogue scale was compared in the two studied groups. In group (A) the mean pain score in the first post-operative day was $9.6 \pm 0.59$ which decreased to $7.9 \pm 0.64$ in the second postoperative day, pre discharge pain score was 5.25 \pm 1.1 . Pain score in group (A) during the first 24 hours was $7.7 \pm 0.65$. This score decreased 3 in the second post-operative day to $5.7 \pm 0.97$, while pre discharge, it was $3.5 \pm 1$. This data shows that pain was less in group (B) with highly statistically significant difference

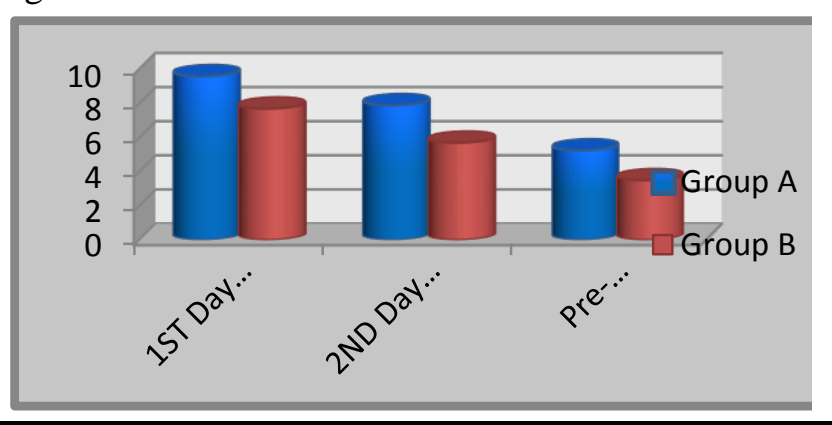

Figure 12 : showing pain score in both groups
Table 9 : showing patients satisfaction about their wound scar

\begin{tabular}{|l|l|l|}
\hline & $\begin{array}{l}\text { GROUP } \\
\text { A }\end{array}$ & $\begin{array}{l}\text { GROUP } \\
\text { B }\end{array}$ \\
\hline $\begin{array}{l}\text { Wound } \\
\text { Satisfaction }\end{array}$ & $\begin{array}{l}14 \\
(93 \%)\end{array}$ & $2(13 \%)$ \\
\hline
\end{tabular}

This table showed that Satisfaction of Wound was comparable in group B showed that 13 cases $(87 \%)$ were not satisfied about their wound scar and only 2 case $(13 \%)$ were satisfied about their wound scar, while 14 cases $(93 \%)$ of group A were satisfied about their wound scar after minithoracotomy which was very small compared to wound scar after sternotomy. P value was less than 0.0001 denoting that there was highly statistically significant difference between two group.

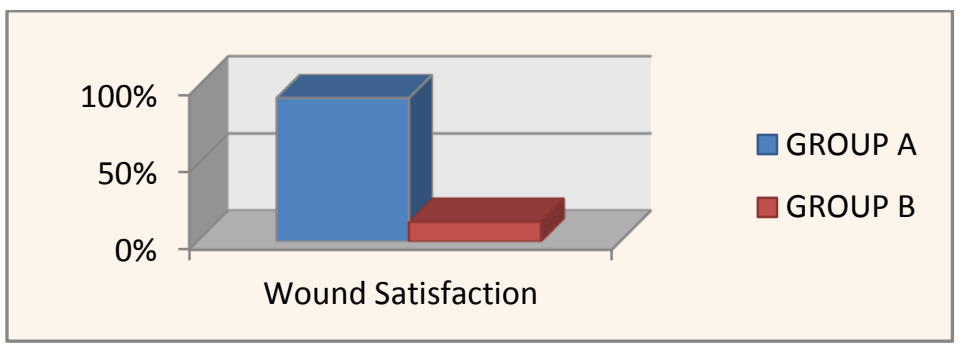

Figure 13: showing patients satisfaction about their wound scar

Table10: showing hypertrophy of the scar and patients satisfaction about their wound in both groups after 3 months post-operative

\begin{tabular}{|l|l|l|}
\hline & $\begin{array}{l}\text { Group } \\
\text { A }\end{array}$ & $\begin{array}{l}\text { Group } \\
\text { B }\end{array}$ \\
\hline Hypertrophic scar & $1(7 \%)$ & $3(20 \%)$ \\
\hline $\begin{array}{l}\text { Patients } \\
\text { satisfaction }\end{array}$ & $\begin{array}{l}14 \\
(93 \%)\end{array}$ & $5(33 \%)$ \\
\hline
\end{tabular}

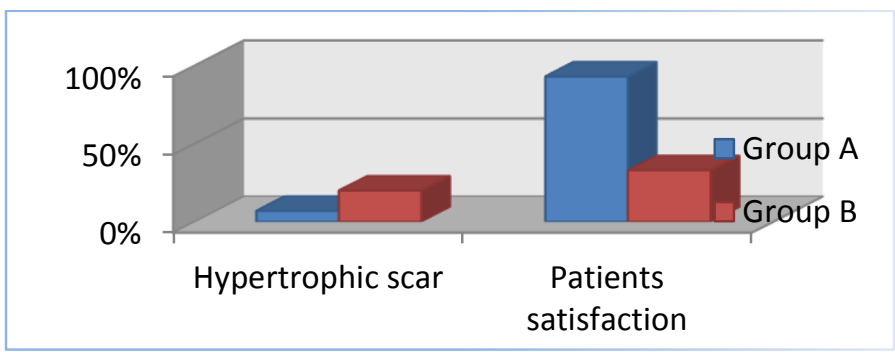

Figure 14: showing hypertrophic scar and patients satisfaction about their wound in both groups after 3 months post-operative 
Table 11: show pain score after 3 months in both groups

\begin{tabular}{|l|l|l|}
\hline & $\begin{array}{l}\text { GROUP } \\
\text { A }\end{array}$ & $\begin{array}{l}\text { GROUP } \\
\text { B }\end{array}$ \\
\hline Pain score & 1.6 & 3.45 \\
\hline
\end{tabular}

This table showed that Pain score After 3 months the pain score using the visual analogue scale was compared in the two groups. Pain score in group (I) was $3.45 \pm 0.998$, in group (II) the mean pain score was $1.6 \pm 0.68$. with highly statistically significance difference

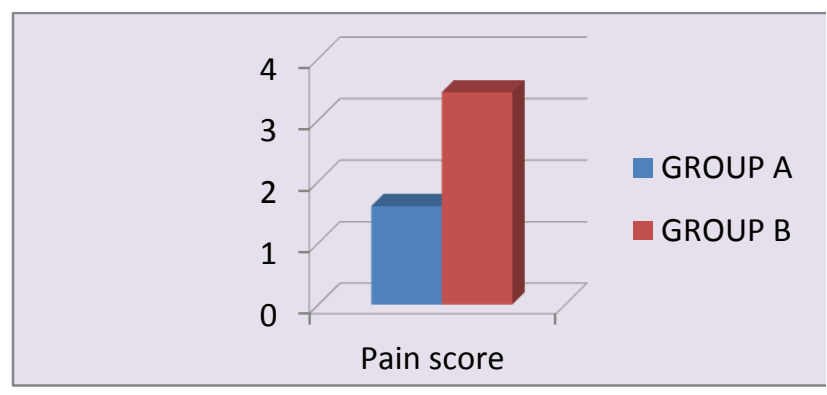

Figure 14: showing Pain score after 3 months in both groupsp

\section{Discussion}

Since starting the era of open heart surgery in 1953, sternotomy has been the standard surgical approach to repair ASD ${ }^{(7)}$.Unfortunately, sternotomy incision was associated with many negative outcomes including poor cosmetic appearance and potential serious infections as osteomyelitis, and mediastinitis ${ }^{(\mathbf{8})}$.

Recently, many invasive surgical procedures were used to achieve excellent cosmetic results. These Many invasive surgical approaches involved upper and lower partial-sternotomy ${ }^{(\mathbf{9})}$, anterior left thoracotomy ${ }^{(10,11)}$., transxiphoidal approach without sternotomy ${ }^{(12,13)}$.RALT ${ }^{(7)}$ or posterior lateral thoracotomy ${ }^{(\mathbf{1 3})}$.

Many of surgeons had prefer right anterolateral minithoracotomy (RALT) to repair ASD ${ }^{(14)}$. Particularly in female patients from the surgical anatomical point of view, sternotomy incision offers direct access to the heart from front and the RALT approaches of the heart from different directions. However, using RALT had some benefits for the patients. RALT technique was a smaller associated with less operative trauma and minimal adhesions behind the sternum that help in any future mediastinal surgeries. Moreover, it preserved the stability and integrity of the thorax cage resulting in less pain and superior postoperative recovery and quick return to daily activities. In addition, it has been reported that it had less resource consumption, and shorter hospital stay resulting in decreased costs ${ }^{(15)}$.On the other hand, some negative drawbacks for the RALT including breast and pectoral muscle mal-development that was reported in $7.4 \%$ of patients ${ }^{\mathbf{( 1 6 , 1 7 )}}$ or phrenic nerve injury ${ }^{(\mathbf{1 8}}$. However, another study reported no substantial breast deformity and phrenic injury in long term follow-up ${ }^{\left({ }^{19}\right)}$. Other limitations of the RALT were struggling in establishing CPB circulation, long operating time and postoperative thoracotomy pain ${ }^{(\mathbf{1 8})}$. The RALT was mainly an antero-lateral incision so the likelihood of affecting the latissimus dorsi and the spinal muscles is unlikely to occur ${ }^{(20)}$.

In our pilot randomized controlled trial (RCT), 30 patients with ASD were assigned to two groups. Group A (15 patients) who underwent RALT, and group B (15 patients) who were operated via the conventional sternotomy. Both groups were comparable except for sex where more females $(80 \%)$ were allocated in the RALT group and our findings are in line with other study ${ }^{(21)}$.Nonetheless, this coincident finding is not a major issue in males considering that hair growth may mask the effects of the sternotomy incision (20). We used single lumen instead of double endo tracheal tube for lung ventilation in group A to avoid possible lung injury, stretch of lung, and pleural damage reported by other investigators $^{(\mathbf{2 2})}$.due to use of one-lung ventilation. Typically, RALT incision varies between 4 and $8 \mathrm{~cm}{ }^{(23)}$. which was much shorter than those of the former sternotomy with better cosmosis ${ }^{(22)}$.

The length of the incision was smaller than the length in our study, in which the RALT incision varied between 8 and $10 \mathrm{~cm}$ in length. We think that the difference was because of usage of central cannulation in our study. In our study, we cannulated ascending aorta from the RALT incision to avoid groin incision and avoid its potential complications. Moreover, our incisions length provided better operating and visualfield similar to the results of other studies (20,26). 
However, other investigators (15,27,28) recommended the femoral cannulation for CBP conduction to operate at a comfortable field when small-sized cannulas were used and they did not notice any major complications with this technique.

In group A, we used induced cardioplegic arrest with aortic clamping. In group B, continuous cardiac perfusion with ventricular fibrillation was sufficient for myocardial protection supporting Nezafati et al.study ${ }^{(27)}$.

No one of our patients needed conversion to sternotomy incision in compairing with Poyrazoglu study (29) .Other investigators, Mishra et al. (30) reported conversion to sternotomy in some cases occurred due to inability to obtain satisfactory central arterial cannulation. Dabritz and Thosani RM (15,26) adoptted a tension-free direct closure technique in patients had a longitudinal defect with sufficient overlapping tissue reported residual defect in 3 of our patients detected by echocardiography predischarge besides the intraoperative transesophageal echocardiography did not detect any of them. However, those residual defects did not require reoperation. Although, we found highly statistically significant difference between the two studied groups regarding total CPB time (minute) with p-value 0.004, the two groups had similar total operative time (hours) with $\mathrm{p}$-value 0.320 supporting previous study ${ }^{(4)}$ Our study had a longer operative time in the thoracotomy group because of operating in a restricted space in the minithoractomy incision. Other studies who used aortic cross clamp in minithoractomy incision sitting found similar cross clamp time and CPB in RALT vs sternotomy ${ }^{(29,31)}$

Generally, it was concluded that aortic crossclamp time in the RALT procedure would imply the struggle during surgery. Other study proved a longer aortic cross-clamp time in RALT, but it was insignificant ${ }^{(22)}$.Average reduction in cross clamp time and CPB time may be attributed to the increased use of direct closure technique (26). Another finding in our study was significantly prolonged ventilation time in the sternotomy group (p-value $1 / 40.002$ ). The total chest tube drainage, allogeneic blood transfusion rate, ICU stay, and hospital length of stay were similar ( $\mathrm{p}$ -

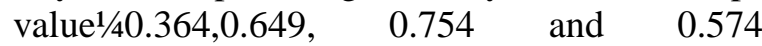
respectively) in coherence with previous published research Gaetano P study ${ }^{(22)}$. Poyrazoglu et al. ${ }^{(29)}$ recommended RALT approach. They think that besides it was a safe incision, RALT when compared to sternotomy had less drainage, reduced transfusion rate, and less re-exploration due to postoperative bleeding due to absence of the larger raw and oozing sternal surface area resulting in shorter ICU time of stay On contrary, others investigators (31) reported that equivalent chest tube drainage, mechanical ventilation, ICU stay and mean CPB times between the patients of sternotomy and RALT groups. None of our study patients had any remarkable limitation to movements of the right shoulder. However, other researchers ${ }^{(26)}$ reported that limitation of shoulder movements inducedpain was one of the postoperative morbidities after thoracotomy. The sternotomy group presented statistically significant increased superficial infection rate in compairing with previous researches ${ }^{(15,30)}$. All our patients in our study were alive till the last follow-up (onemonth post hospital discharge) and there was no any residual defect on their follow-up echocardiography.

\section{Conclusion}

Right antero-lateral mini thoracotomy technique for atrial septal defect closure is safe and reliable technique as sternotomy incision technique. A cause of its restricted operating field and longer pump-run time, it keeps the sternal integrity, it has better esthetic incision, it reduces wound infection and the need for analgesia. Moreover, it is associated with an early recovery and short ICU stay.

\section{REFERENCES}

1. Stark M, de Leval and Tsang V (2006): surgery for congenital heart defects. $3^{\text {rd }}$ ed. john wiley England.

2. Lamelas J. Nguyen T (2015): Minimally invasive valve surgery: when less is more. Semin. Thoracic Surg., 27:49-56.

3. Bigdelian H, Sedighi M and Movahedi F( 2015): Repair of atrial septal defect via right submammary minithoracotomy in children. Int. Cardiovasc. Res. J., 9(1):52-56.

4. da Silveira WL, Bosco FAP, Leite AF, Peixoto FAO, de Sousa M and de Souza C (2007): Correction of simple congenital 
heart defects in children and adolescents through minithoracotomies. Arq. Bras. Cardiol., 88(4):358-367

5. Saadat S, Schultheis M, Azzolini A, Romero J, Dombrovskiy Vand Odroniec K et al. (2016): Femoral cannulation: a safe vascular access option for cardiopulmonary bypass in minimally invasive cardiac surgery.Perfusion.https://www.ncbi.nlm.nih. gov/pubmed/26034193

6. Bisdas T, Beutel G, Warnecke G, Hoeper MM, Kuehn $\mathrm{C}$ and Haverich A et al. (2011): Vascular complications in patients undergoing femoral cannulation for extracorporeal membrane oxygenation support. Annual Thorac. Surg., 92(2):626 636 .

7. Abdel-Rahman U, Wimmer-Greinecker G, Matheis G and Moritz A (2001): Correction of simple congenital heart defects in infants and children through a minithoracotomy.Ann.

Thorac. Surg.,72(5):1645-1654.

8. Nicholson IA, Bichell DP, Bacha EA and del Nido PJ( 2001): Minimal sternotomy approach for congenital heart operations. Ann. Thorac. Surg., 71:469474.

9. Rao V and Freedom RM( 1999): Minimally invasive surgery with cardioscopy for congenital heart defects. Ann. Thorac. Surg., 68:1742-1747.

10. Ho AC, Chen CK, Yang MW, Chu JJ and Lin PJ ( 20 04): Usefulness of intraoperative transesophageal echocardiography in the assessment of surgical repair of pediatric ventricular septal defects with video-assisted endoscopic techniques in children. Chang. Gung. Med. J., 27:646 -653.

11. Chan CY, Chiu IS, Wu SJ and Hung CR ( 2001): A minimal transverse incision with low median sternotomy for pediatric congenital heart surgery. Eur. J. Cardiothorac. Surg.,19:290-293.

12. Pretre R, Kadner A, Dave H, DodgeKhatami A, Bettex $D$ and Berger $F$ (2005):Right axillary incision: a cosmetically superior approach to repair a wide range of congenital cardiac defects. J. Thorac. Cardiovasc. Surg., 130:277281.
13. Liu YL, Zhang HJ, Sun HS, Li SJ, Su JW and Yu CT (1998): Correction of cardiac defects through a right thoracotomy in children.J. Thorac. Cardiovasc. Surg., 116(2):359-361.

14. Doll N, Walther T, Falk V, Binner C, Bucerius $\mathrm{J}$ and Borger MA et al.(2003): secundum ASD closure using a right lateral minithoracotomy:five-year experience in122 patients. Ann. Thorac. Surg.,75:1527-1531.

15. Dabritz S, Sachwek J, Walters $M$ and Messmer BJ ( 1999): Closure of ASD via limited right anterolateral thoracotomy as minimal invasive approach in female patients. Eur. J. Cardiothorac. Surg.,15:1823.

16. El-Minshawym A, Roman KS, Kamlin O, Salmon AP and Haw MP(2003) Minimally invasive surgical closure of secondum ASD defect: safety and efficacy? J. Egypt. Soc. Cardiothorac. Surg.,2:233-242.

17. Helps BA, Ross-Russell RI, Dicks-Mireaux $C$ and Elliott MJ(1993): Phrenic nerve damage via a right thoracotomy in older children with secondum ASD. Ann. Thorac. Surg.,56: 328-333.

18. Muralidharn S, Krishnan VA, Varma $S$ and Nagarajan M.(2004): ASD closure in young female by an anterolateral thoracotomy. Ind. J. Thorac. Cardiovasc. Surg.,20:129e31.

19. Gil-Jaurena JM, Murtra M, Gonçalves A, Mir o L, Vilaa $R$ and García-Gorriza M.(2002): Comparative study of thoracic approaches in atrial septal defect closure. Rev. Esp. Cardiol., 55(11):1213-1216.

20. Palma G, Giordano R, Russolillo V, CioffiS, Palumbo $S$ and Mucerino M. et al.(2009): Anterolateral minithoracotomies for the radical correction of congenital heart diseases. Tex. Heart Inst. J., 36(6):575-584.

21. Ding C, Wang C, Dong A, Kong M, Jiang $D$ and Tao K. et al.(2012): Anterolateral minithoracotomy versus median sternotomy for the treatment of congenital heartdefects: a meta-analysis and systematic review. J. Cardiothorac. Surg.,7:43-54.

22. Gaetano P, Raffaele G, Veronica R, Sabato $\mathrm{C}$, Sergio $\mathrm{P}$ and Marco $\mathrm{M}$ et 
al.(2009):Anterolateral minithoracotomies for the radical correction of congenital heart defects. Tex. Heart Inst. J.,36(6):575-584.

23. Jung SH, Je HG, Choo SJ, Yun TJ, Chung CH and Lee JW(2010): Right or left anterolateral minithoracotomy for repair of congenital ventricular septal defects inadult patients. Interact. Cardiovasc. Thorac. Surg., 10: 22-28.

24. Ramsankar P, Sadanandan R, Abdul Rasheed MH, Nampoothiri MNY, Dinakaran KG and Nair PB (2005): Right postero-lateral thoracotomy for atrial septal defectclosure; a comparative analysis with median sternotomy. Ind. J. Thorac. Cardiovasc. Surg., 21:24-32.

25. Formigari R, Di Donato RM, Mazzera E, Carotti A, Rinelli G, Parisi F et al.(2001): Minimally invasive or interventional repair of atrial septal defects in childrenexperience in 171 cases and comparison with conventional strategies. JACC., 37(6):17071712.

26. Thosani RM, Shah BK, Gandhi HG, Sharath Kumar K and Rawal JR (2013): A modified anaesthesia protocol for patients undergoing minimal invasive cardiac surgery by right thoracotomy- a single center experience. Indian J. Appl. Basic Med. Sci., 15(20):82-95.
27. Nezafati MH, Nezafati $P$, Hosseinzadeh $M$ and Tehrani SO.(2015): Minimally invasive mitral valve surgery via minithoracotomy and direct cannulation. Asian Cardiovasc. Thorac. Ann.,23: 271-275.

28. Vollroth M, Seeburger J, Garbade J, Pfannmueller B, Holzhey D and Misfeld B (2012): Minimally invasive mitral valve surgery is a very safe procedure with very low rates of conversion to full sternotomy. Eur. J. Cardiothorac. Surg., 42:13-18.

29. Poyrazoglu HH, Avsar MK, Demir S, Karakaya Z, Güler T and Tor F (2013): Atrial septal defect closure: comparison of vertical axillary minithoracotomy and median sternotomy. J. Thorac. Surg., 46: 340-345.

30. Mishra YK, Malhotra R, Mehta Y, Sharma KK, Kasliwal RR and Trehan N (1999): Minimally invasive mitral valve surgery through right anterolateral minithoracotomy. Ann. Thorac. Surg., 68:1520-1524.

31. Aarabi Moghadam MY, Shah Mohammadi AA, Meraji SM, Davari PN, Omrani GR and Miri SR (2008): Right anterolateral thoracotomy as an alternative to mediansternotomy for repair of atrial septal defect: a cosmetic approach for female patients. Iran Heart J.,9 (1):29-33. 